\title{
Pineal melatonin rhythms and the timing of puberty in mammals
}

\author{
F. J. P. Ebling and D. L. Foster
}

Reproductive Sciences Program, and Departments of Obstetrics and Gynecology, and Biology, The University of Michigan, 300 North Ingalls Building, Ann Arbor (Michigan 48109-0404, USA)

Summary. The direction of change in daylength provides the seasonal time cue for the timing of puberty in many mammalian species. The pattern of melatonin secretion from the pineal gland transduces the environmental lightdark cycle into a signal influencing the neuroendocrine control of sexual maturation. The change in duration of nocturnal melatonin secretion is probably the key feature of the melatonin signal which conveys daylength information. This information may also be used by neuroendocrine axes controlling seasonal changes in pelage colour, growth and metabolism. The mechanism of action of melatonin on neuroendocrine pathways is unknown. Although the ability to synthesize and secrete melatonin in a pattern that reflects the duration of the night may not occur until the postnatal period, the rodent and ovine foetus has the ability to respond in utero to photoperiodic cues to which its mother is exposed in late gestation. Transplacental passage of maternal melatonin is likely to be the mechanism by which photoperiodic cues reach the foetus. Species which do not exhibit seasonal patterns of puberty, such as the human, also secrete melatonin in a pattern which reflects the environmental light-dark cycle, but they do not respond reproductively to the seasonal melatonin information.

Key words. Puberty; photoperiod; pineal; melatonin.

\section{Multiple factors time puberty}

This review will focus on recent developments in understanding the role of photoperiod, and in particular, that of the pineal gland, in timing puberty in mammals. Puberty has variously been defined as the gradual process of sexual maturation, or as a discrete event, the first time at which an animal is capable of conception; in this review, puberty will be loosely considered as the attainment of adult reproductive function. Clearly, many factors other than photoperiod influence the timing of puberty, and the role of these other factors in interpreting experiments designed to reveal photoperiodic influences should be borne in mind. The most fundamental determinant for puberty relates to growth requirements, that is, an individual must achieve a certain degree of somatic development for reproductive maturation to proceed. Studies in many species demonstrate that reproductive maturation is delayed when growth is retarded by means of dietary restriction $^{17,31,49}$, but we have little understanding of what the developmental growth requirements are for any species, or how such growth and nutrition-related factors interact with the neuroendocrine axis controlling reproduction ${ }^{10,77}$. Social cause, be they stimulatory or inhibitory, may also exert a major influence on the timing of puberty ${ }^{8}$. In this regard, the results of several early studies raised doubts that photoperiod modulates the timing of puberty in female sheep. However, those investigations were flawed because they used adult male rams to detect sexual behaviour, onset of oestrus being a marker of puberty ${ }^{19,61,73}$, and subsequent studies have revealed that introduction of rams to prepubertal sheep can, in itself, induce gonadotrophin secretion and puberty ${ }^{59,75}$. Thus, the effects of photoperiod on puberty in the original experiments in sheep may well have been obscured by exposure of the developing lamb to the social influences of mature males. In addition, seasonal photoperi- odic cues may also influence growth and metabo$\operatorname{lism}^{2,3}, 25,28,36$, thus the potential exists for indirect effects of photoperiod on the timing of puberty by means of altered growth and body composition.

\section{Photoperiodic influence on puberty}

Puberty in many different mammalian groups inhabiting seasonal environments is seasonal, a strategy of sexual maturation which presumably evolved as a mechanism to ensure that subsequent offspring are born at the optimal time of year ${ }^{27}$. The list of species, in addition to rodents (e.g., Djungarian hamster ${ }^{7,42}$ ), which have been shown experimentally to respond to photoperiod as the seasonal time cue is growing. It encompasses ruminants (e.g., sheep ${ }^{30,32,34}$ ), lagomorphs (e.g., European rabbit ${ }^{6}$ ), mustelids (e.g., ferret ${ }^{68,69}$ ), carnivores (e.g., blue fox ${ }^{72}$ ), and even primates (e.g., rhesus monkey $90,93,94)$. This review is not intended to provide a bibliography of species in which photoperiod times puberty; rather, we will focus on two species which have been used experimentally as model systems to unravel mechanisms by which environmental photoperiod influences neuroendocrine function, namely the Djungarian hamster and sheep. In a final section, we consider if photoperiodic cues influence the timing of puberty in children.

The mechanism by which photoperiodic signals influence reproduction in the adult has been discussed in detail in a companion review (Bartness and Goldman, this issue) ${ }^{4}$. Much of our understanding of the mechanisms underlying the control of sexual maturation comes from studies of seasonal breeding in adult mammals, but it is worth noting that the developing mammal itself has equally provided a model for understanding photoperiodic mechanisms in the adult ${ }^{11,12,38}$. In this regard, photoperiodic effects on the timing of the first breeding season 
(i.e., puberty) may be more rapid and more easily manipulated in several species (e.g., Djungarian hamster, sheep) than they are for subsequent annual reactivation of reproductive function as fully mature individuals.

\section{Photoperiod cues time an endogenous maturational process}

The terms 'long-day breeder' and 'short-day breeder' have been used historically to describe the photoperiodic conditions under which a particular species attains puberty or undergoes seasonal reactivation of reproduction. These terms may be misleading because they suggest that the photoperiodic requirements for onset of reproductive activity in a given species are simply that it experiences a particular length of day. For example, the spring-born female sheep normally attains puberty during the short days of the subsequent autumn, the time at which the adult female sheep resumes oestrous cycles $^{34,46}$. This observation may lead to the simple conclusion that once growth requirements have been met during the summer, the lamb must wait until daylength becomes shorter to activate its reproductive system for the first time. However, this inference is not valid, as evidenced by the finding that maintaining the lamb on a short photoperiod from birth does not advance puberty, rather, puberty is delayed ${ }^{95}$. To respond to the short-day photoperiod, the developing female sheep must first experience long-day photoperiodic information. Thus, for species which require several months for sexual maturation to occur, a history of changing photoperiod may be necessary to provide seasonal information. It is evident from studies of the lamb that changes in the environmental light-dark cycle may advance or delay puberty such that it occurs in the optimal season, but 'inhibitory' photoperiod signals cannot forestall puberty indefinitely. For example, although female sheep maintained on long days from early in life do not undergo puberty at the normal age of 5-6 months, they do so eventually, albeit at a much later age, typically when they are older than one year ${ }^{20,95}$. These observations have led to the hypothesis that photoperiod acts to entrain an endogenous process to the optimal season, rather than directly to drive or inhibit reproductive maturation ${ }^{20}$.

For species which mature more rapidly, a constant photoperiod may provide adequate seasonal information, at least under experimental conditions. For example, constant long days serve as a stimulatory signal for puberty in the Djungarian hamster; testicular development is complete by approximately two months of age in hamsters maintained on a long-day photoperiod, whereas testicular development is delayed in hamsters chronically exposed to a short photoperiod (fig. 1) ${ }^{97}$. Those placed on short days at birth initially have a slow rate of testicular development, but they do eventually develop full testicular function at five months of age ${ }^{42}$. The observation that in rapidly developing species puberty will occur

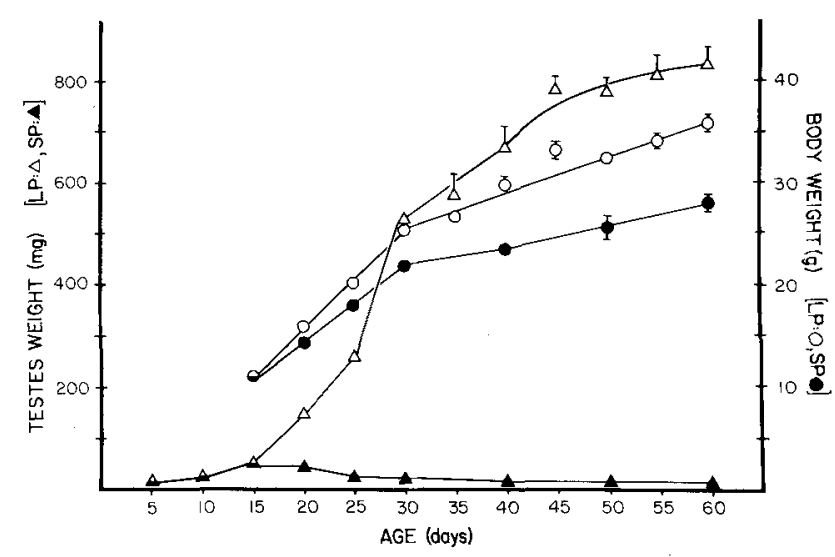

Figure 1. Effects of photoperiod on development in male Djungarian hamsters. Hamsters were raised in long days of $16 \mathrm{~h}$ light: $8 \mathrm{~h}$ dark (LP: $\triangle$, paired testis weight; $O$, body weight), or short days of $10 \mathrm{~h}$ light: 14 h dark (SP: $\boldsymbol{\Lambda}$, paired testis weight; $\boldsymbol{\bullet}$, body weight). Note that long photoperiod stimulates both testis development and somatic growth. (From Yellon and Goldman ${ }^{97}$ ).

eventually under photoperiodic conditions which are initially inhibitory to reproductive development, albeit at a much delayed age, again supports the hypothesis that the role of photoperiod is to provide seasonal time cues to entrain an endogenous process. The seasonal reinitiation of reproductive activity in adult hamsters can also be shown to occur spontaneously on short photoperiods ${ }^{36}$. Thus, the term 'long-day breeder' is inappropriate for this species when used to describe the mechanism by which photoperiod modulates reproductive function, because the mechanism by which seasonal onset of reproductive function occurs may have as much to do with a loss of response to the initially inhibitory effects of short days as it does to the stimulatory effects of long days.

\section{Changing daylength provides the seasonal time cue}

Under natural conditions, it is the direction of change in daylength that provides seasonal information. For example, whereas puberty in spring-born lambs reared on either constant short days or constant long days is delayed beyond one year of age ${ }^{95}$, lambs receiving a long-day photoperiod followed by a short-day photoperiod undergo puberty 6-8 weeks after the decrease in photoperiod (fig. 2, top) ${ }^{32,33,35}$. Thus, a change in photoperiod is the critical photoperiodic cue for puberty in the sheep. Evidence that sheep respond to the direction of the change, rather than the absolute photoperiod, has recently been obtained. Adult female sheep placed on an intermediate photoperiod of 13L:11D after pretreatment with a long day of $16 \mathrm{~L}: 8 \mathrm{D}$ respond to the intermediate photoperiod as a short day, and rapid onset of reproductive activity occurs. Conversely, adult ewes pretreated with short days of $10 \mathrm{~L}: 14 \mathrm{D}$ respond to $13 \mathrm{~L}: 11 \mathrm{D}$ as a long day, and reproductive activity rapidly ceases 65 . Thus, the adult sheep uses its photoperiodic history to determine the direction of change in photoperiod. The same conclusion 


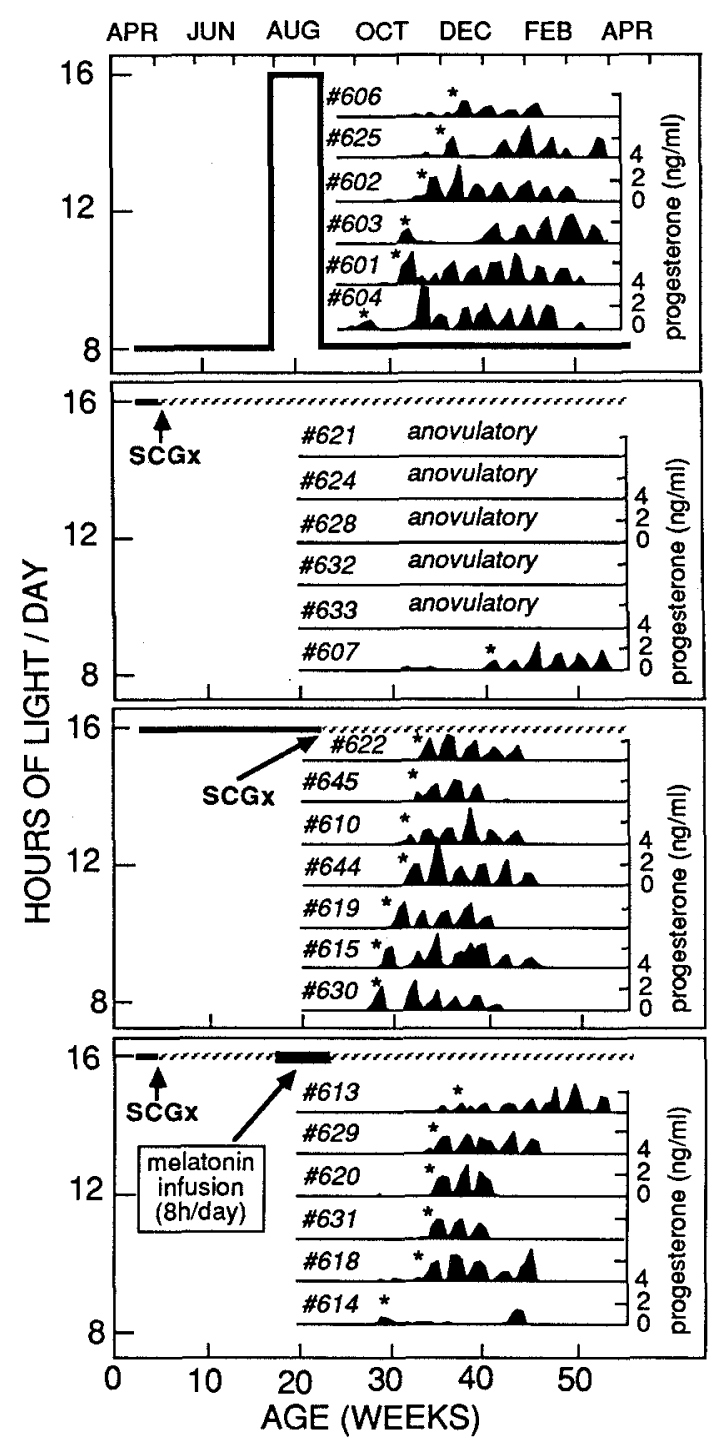

Figure 2. Puberty in female lambs in artificial photoperiod. Puberty (*) is defined as the onset of repetitive oestrous cycles, identified by luteal phase rises in serum progesterone concentrations. Top panel: control lambs raised on a permissive sequence of photoperiods of short days ( $8 \mathrm{~h}$ light: $16 \mathrm{~h}$ dark), then long days ( $16 \mathrm{~h}$ light: $8 \mathrm{~h}$ dark), then short days. Note that puberty occurs at 30-35 weeks of age. Second panel: lambs raised only on long days, but superior cervical ganglionectomized at 3-4 weeks of age to ablate pineal melatonin secretion. Note that puberty is absent in the first year of life or delayed in the absence of photoperiod information. Third panel: lambs raised only on long days, but superior cervical ganglionectomized at 22 weeks of age to ablate pineal melatonin secretion. Note that the experience of long days early in life followed by blocked photoperiod transduction also permits the normal timing of puberty. Bottom panel: lambs raised only on long days, superior cervical ganglionectomized at 3-4 weeks of age to ablate pineal melatonin secretion, but receiving a long-day melatonin infusion for 5 weeks starting at 18 weeks of age. Lambs received melatonin for $8 \mathrm{~h}$ per day. Note that the normal timing of puberty is restored by providing a long-day signal followed by no melatonin information. (Modified from Foster et al. ${ }^{33}$ ).

has been reached from similar studies in the adult Syrian and Djungarian hamster ${ }^{41,43}$. Although the requirement for a changing photoperiod for the normal timing of puberty may not be necessary in experimental situations in the rodent, there is recent evidence that the reproduc- tive response to a constant postnatal photoperiod is influenced by the photoperiodic history of the foetus in utero (see Bartness and Goldman, this issue) ${ }^{4}$. Thus, it is likely that under natural conditions rapidly maturing species do use change in photoperiod as the seasonal time cue, that is, they measure the length of the postnatal photoperiod relative to the prenatal photoperiod.

\section{The pineal gland and melatonin secretion}

There is much support for the view that the pineal gland transduces environmental photoperiod into a melatonin signal, which ultimately influences reproductive and somatic development. The corollaries of the argument that changing photoperiod provides a seasonal time cue is that melatonin itself is not pro- or anti-gonadal per se, but that it is the pattern of its secretion that transduces daylength into a humoral signal. Therefore, whether the melatonin signal provides stimulatory or inhibitory information depends on the previous history of melatonin secretion, and on how the species has evolved to use the timekeeping signal provided by melatonin. The several arguments against melatonin being directly antigonadal or progonadal will be presented throughout the remainder of the review.

The central role of the pineal gland in timing puberty has been demonstrated in several photoperiodic species. Removal or denervation of the pineal gland prevents the inhibitory effects of short days in several species which normally mature under increasing daylengths ${ }^{11,13}$. In the sheep, which requires the alternate sequence of long and then short days for puberty, pinealectomy shortly after birth delays the onset of reproduction ${ }^{48}$. Likewise, if pineal function is disrupted by lesion of the sympathetic innervation to the gland (superior cervical ganglionectomy) shortly after birth to ablate the nocturnal increase in melatonin secretion, puberty is delayed (fig. 2) ${ }^{33,96}$. Interestingly, denervation of the pineal gland after the sheep has experienced a long-day photoperiod will allow puberty to occur subsequently on long days (fig. 2$)^{33}$. This is presumably because disruption of pineal gland function after the obligatory exposure to long days blocks the transduction of inhibitory long-day cues which would delay puberty if continuously experienced during the later stages of development ${ }^{20,95}$.

There is good reason to believe that melatonin is the pineal hormone which mediates the photoperiodic response during development. Replacement of melatonin in a precise manner to pinealectomized or ganglionectomized animals replicates the effects of photoperiod on many seasonal axes, including prolaction secretion ${ }^{33}$, body weight and carcass composition ${ }^{2,3}$, pelage colour and thermoregulation (for review see Goldman and Darrow ${ }^{37}$ ). The elegant studies by Carter and Goldman in the Djungarian hamster ${ }^{1,12}$ clearly demonstrate that melatonin provides a seasonal cue, rather than simply a pro- or antigonadal stimulus. Mimicking the effects of 
short-day photoperiods early in life by infusion of relatively long daily durations of melatonin ( $>8 \mathrm{~h}$ per day) to pinealectomized prepubertal males prevents testicular development ${ }^{11}$. Conversely, hamsters maintained on short days early in life, then pinealectomized at 23 days of age, have a rate of testicular development intermediate between the rapid rate in intact hamsters transferred from short to long days at that age, and the virtual lack of development in hamsters maintained on short days ${ }^{7}$. Treatment of pinealectomized hamsters in this experimental paradigm with relatively short daily durations of melatonin $(<6 \mathrm{~h}$ per day) induces rapid testicular growth, that is, it provides a long-day photoperiod signal $^{12}$. This would not be expected if melatonin were simply an antigonadal hormone. In addition to demonstrating that melatonin provides a temporal time cue, by varying the amount of melatonin infused per day, and the phase of infusion relative to the environmental lightdark cycle, these studies also provided evidence that the duration of elevated melatonin secretion every $24 \mathrm{~h}$ rather than the amplitude of nocturnal secretion is the key parameter providing daylength information ${ }^{11,12}$. Investigations of how timed infusions of melatonin influence puberty have also been conducted in the female lamb in which the sequence of long days followed by short days is the critical photoperiod signal for sexual maturation. Ablation of the circadian melatonin rhythm shortly after birth delays puberty (fig. 2). Replacement of the melatonin rhythm by timed infusions providing $8 \mathrm{~h}$ of melatonin per day (a 'long-day' duration for the sheep) for only 5 weeks allows the normal timing of puberty $6-8$ weeks after the melatonin infusion ceases (fig. 2 ) $^{33}$. Thus, experimentally, a long-day melatonin signal followed by no melatonin appears to provide a 'decreasing photoperiod' signal for the developing lamb.

A second line of evidence supporting a fundamental role for melatonin is that treatment of pineal-intact animals with melatonin alters the timing of puberty. Several studies have been conducted in the prepubertal sheep with subcutaneous melatonin implants which release the hormone continuously over $24 \mathrm{~h}$. Treatment of Merino female lambs with such implants early in life delays puberty ${ }^{47}$, whereas treatment of lambs at an older age (using vaginal implants) advances the age of puberty ${ }^{58}$; likewise treatment of ram lambs with melatonin implants advances testicular development ${ }^{54}$. Although this experimental approach may produce physiological serum concentrations of melatonin, they are provided in a nonphysiological pattern (i.e., elevated continuously), so only limited conclusions can be drawn about the nature of the photoperiodic signal that constant-release implants provide. Clearly it depends on the previous photoperiodic history of the animals, but the effects on puberty may be equally consistent with the constant signal being a functional pinealectomy (i.e., preventing the animal recognizing its endogenous melatonin pattern) or with it providing a long duration (i.e., short-day) time signal. In this regard, the pubertal delay in the female lamb after initiation of chronic melatonin treatment neonatally would be due to the failure to experience the requisite long-day melatonin signal early in life. Once long days are experienced, chronic melatonin treatments started later in development would then mimic short days (i.e., prevent incoming long-day melatonin signals), and such a treatment can be timed to induce precocious puberty. Aside from these concerns about interpretations of chronic treatments with a hormone which is normally secreted in a circadian pattern, such studies emphasize the marked effects of melatonin on sexual maturation.

\section{Ontogeny of photoperiodic responses}

Birth must be considered as an arbitrary point in the development of a particular species ${ }^{29}$. Thus, it is not surprising that mature pineal function occurs perinatally in precocious species such as the sheep, but postnatally in altricial species such as the rat and Djungarian hamster. Accounts of the morphogenesis of the pineal gland in a variety of species exist $57,81,83$. Ontogeny of melatonin secretion will be briefly considered in the two species upon which we have concentrated, the sheep and the Djungarian hamster. Although, rhythms in serum melatonin concentrations have been detected in the ovine foetus from 113 days of gestation (term is $145-150$ days), this melatonin is probably of maternal origin, because pinealectomy of the mother ablates serum melatonin rhythms in both the maternal and foetal circulation $56,98-100$. Two studies, however, suggest that the newborn lamb can secrete melatonin by about one week postnatally, and that this rhythm is appropriate to the light-dark cycle ${ }^{14,99}$. Thus, pineal function is mature well before reproductive maturation occurs in the sheep. In the Djungarian hamster, until recently ${ }^{16}$, technical problems have limited the study of serum melatonin rhythms, but studies on pineal melatonin content indicate that pineal function matures about 15 days postnatally, that is late relative to the time of puberty ( 50 days of age) in this species ${ }^{79}$. However, considerations of the ontogeny of endogenous pineal function may be of limited value in understanding the development of photoperiodic responses, because recent studies in several species indicate that the foetus can respond to photoperiodic signals transduced by the mother, rather than by its own pineal gland.

Horton $^{45}$ originally demonstrated that the photoperiod to which the pregnant Montane vole is exposed influences postnatal development of the offspring. Specifically, male pups from mothers maintained in long days grew their testes more rapidly than those from mothers housed in short days. These effects were attributable to influences in utero. Cross-fostering of pups born from longday treated mothers to other mothers exposed to short days before parturition, and the reciprocal cross-fostering protocol, revealed that the developmental effects did 
not result from behavioural or lactational signals conveyed by mothers to the pups during postnatal life ${ }^{44}$. Subsequent studies in the Djungarian hamster ${ }^{76}$, and sheep ${ }^{23}$ have provided further evidence that prenatal photoperiod influences postnatal development. Our recent studies in sheep used prolactin secretion as an index of photoperiodic response, because this is a photoperiodically-modulated hormone in the neonatal lamb and the adult; long daylengths are stimulatory and short daylengths are inhibitory $21,22,55$. Also, the effects of photoperiod on prolactin secretion are mediated by pineal melatonin secretion ${ }^{9,22,53}$. Figure 3 illustrates serum prolactin concentrations in female and male lambs raised in an intermediate $(12 \mathrm{~L}: 12 \mathrm{D})$ photoperiod from the day of birth, but born to ewes maintained in either long days (16L:8D) or short days (8L:16D) for the last 50 days of gestation ${ }^{23}$. Not only did prolactin concentrations differ at birth in the lambs from long-day and short-day treated mothers, but the subsequent response to $12 \mathrm{~L}: 12 \mathrm{D}$ differed markedly. Lambs from long-day treated mothers were born with high circulating prolactin, but concentrations declined rapidly, indicating that they interpreted 12L:12D as a short day. Conversely, lambs from shortday treated mothers were born with low serum prolactin concentrations, but prolactin secretion increased, indicating that they responded to $12 \mathrm{~L}: 12 \mathrm{D}$ as a long day.

This study demonstrates two aspects of the foetal response to photoperiodic cues received by the mother. Firstly, photoperiod can modulate neuroendocrine functions in utero, in this case resulting in differential prolactin secretion in the foetus ${ }^{5}$ and at birth ${ }^{23}$. Secondly, even before birth, the lamb begins to construct a photoperiodic history with which it can interpret photoperiodic signals postnatally. Thus, the lambs from long-day exposed mothers respond to the $12 \mathrm{~L}: 12 \mathrm{D}$ photoperiod as a short day because it is a 4-h decrease relative to the photoperiodic signals received in utero. The corollary of the second conclusion is that the foetus is actually receiving photoperiodic time cues, rather than simply responding to other maternal information that was initially influenced by photoperiod. Studies in the Djungarian hamster

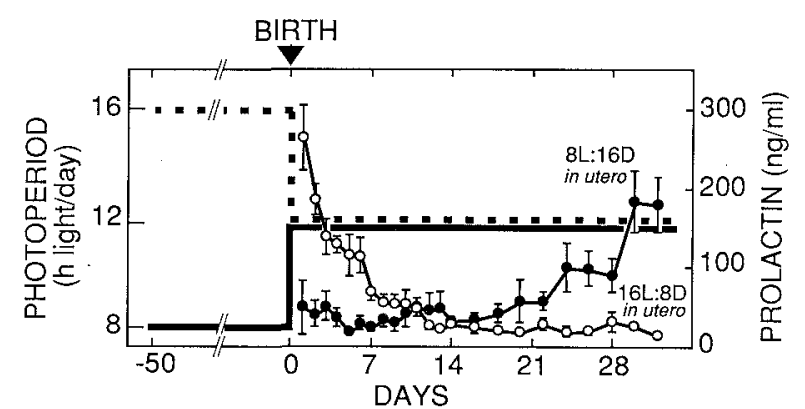

Figure 3. Serum prolactin concentrations in female lambs on $12 \mathrm{~h}$ light: $12 \mathrm{~h}$ dark (12L:12D), born to mothers maintained in $16 \mathrm{~h}$ light: $8 \mathrm{~h}$ dark $(\mathrm{O}, 16 \mathrm{~L}: 8 \mathrm{D})$ or $8 \mathrm{~h}$ light: $16 \mathrm{~h}$ dark $(0,8 \mathrm{~L}: 16 \mathrm{D})$ during late gestation. Note that the photoperiod experienced indirectly by the lamb in utero dictates the pattern of prolaction secretion on the common intermediate 12L:12D photoperiod. (Modified from Ebling et al. ${ }^{23}$ ). provide direct evidence that the pattern of melatonin secretion from the maternal pineal gland conveys photoperiodic information to the foetus during late gestation. Pinealectomy of pregnant hamsters prevents the stimulatory effects of long photoperiods during late gestation on testis development and body weights in male offspring ${ }^{87}$. Infusion of long-day durations of melatonin into pinealectomized mothers in late gestation successfully mimics the effects of long-day treatment on foetal and neonatal development ${ }^{87,88}$. Studies in several species have revealed that placental transfer of melatonin occurs readily ${ }^{50,63,100}$. Collectively, these lines of evidence support the view that it is the pattern of maternal melatonin secretion that transduces photoperiodic information to the foetus.

Intriguingly, recent investigations of the Meadow vole suggest that seasonal information can also reach the foetus via pathways other than melatonin; photoperiodic information received by mothers before conception can influence foetal and postnatal development ${ }^{51,52}$. For example, pups born to mothers housed in a short-day photoperiod for a short period (5-11 weeks) before conception have a greater depth of fur after birth than those born to mothers kept on long days, or on short days for an extended period of time before conception ${ }^{51,52}$. It is not known through which maternal systems the preconception photoperiod operates to produce the subsequent differences in neonatal response. It is most unlikely to be the circadian melatonin profile, because the pattern to which the foetus is exposed would only reflect ambient photoperiod during gestation, not the previous photoperiodic history of the mother.

\section{Developmental changes in response to photoperiod}

We have considered evidence in the Djungarian hamster and sheep that melatonin-mediated photoperiodic cues influence neuroendocrine function throughout development, from late gestation to the mature adult. The Syrian hamster is unusual in that there is developmental change in the reproductive response to photoperiod. Photoperiod is a major modulator of reproduction in the adult Syrian hamster ${ }^{37}$, but does not seem to influence sexual maturation. The initial rate of testicular development is similar in males raised in short days or in long days from birth. Mature size and function are attained at about 8 weeks of age irrespective of ambient photoperiod; beyond that age, rapid gonadal regression occurs in shortday housed hamsters ${ }^{15,67,71}$. Furthermore, melatoninimplant treatments which induce gonadal regression in adult males maintained in long days are ineffective in retarding prepubertal testicular development in this spe$\operatorname{cies}^{80}$. Such findings have led to the conclusion that photoperiodic modulation of reproductive function begins after puberty in this species. On the other hand, some workers have postulated that the Syrian hamster is able to discriminate daylength after pineal function ma- 
tures at about 15 days postnatally, but that the latency of the reproductive response to the short days (regression of testes) is longer than the time required for gonadal maturation in this species ${ }^{64,66}$. This would explain why inhibitory effects of short days are not apparent until after puberty. Sisk and Turek ${ }^{71}$ challenge this notion. They studied developmental patterns of gonadotrophin secretion in castrated hamsters bearing testosterone implants to provide a constant negative feedback signal. They failed to find effects of photoperiod on sensitivity to testosterone negative feedback in prepubertal males, even though changes in sensitivity occur rapidly $(2-3$ weeks) in mature males exposed to a change in photoperiod. Thus, neuroendocrine events associated with puberty occur independently of photoperiod in this species, and the slow response of the testis to endocrine signals during development cannot explain the inability to respond to short days.

The opposite situation applies to the most intensively studied mammal, the laboratory rat. In these highly inbred animals living in artificial conditions, prepubertal gonadal maturation is influenced to some extent by daylength, whereas reproductive function in the adult is largely insensitive to photoperiod ${ }^{62,86}$. This presumably reflects artificial selection for prolific and rapid breeding ${ }^{62,86}$. It is interesting to note that more pronounced photoperiodic effects on puberty are revealed when immature rats are raised on restricted nutrition ${ }^{74}$, suggesting that underlying photoperiodic influences are normally being masked in artificial environmental and nutritional conditions.

\section{Melatonin and human puberty}

The preceding sections summarize evidence that photoperiod influences the timing of puberty in seasonal mammals. Initially, the pattern of melatonin secretion from the maternal pineal gland provides seasonal time cues for the developing foetus. Subsequently, endogenous melatonin secretion develops in the prepubertal mammal, and the changing duration of nocturnal melatonin secretion provides the requisite seasonal information. In view of this rather straightforward scheme to coordinate sexual maturity with the optimal season for conception, we can now consider if the pineal gland plays an important role in the timing of puberty in our own species. Studies in infant children have demonstrated that a nocturnal increase in circulating melatonin develops between birth and three months of age ${ }^{1,40}$. Nocturnal melatonin concentrations are low during the phase of postnatal elevation of gonadotrophin and testosterone secretion, and they increase as the neonatal phase of testicular activity in the male decreases ${ }^{40}$. Considerable attention has focussed on the subsequent decline in amplitude of nocturnal melatonin secretion during the transition into adulthood which has been noted in several clinical studies $39,70,84,85$, and in a longitudinal study of the female rhesus monkey ${ }^{92}$. Such observations, coupled with historical reports of precocious puberty in boys with pineal tumors ${ }^{39}$, have led to the hypothesis that pineal melatonin has an antigonadal role in the human. This leads to the further inference that a reduction in nocturnal secretion is one factor underlying the onset of puberty. It should be noted that not all the workers who have reported a nocturnal decrease in melatonin secretion have reached the same conclusion; moreover, some studies have failed to detect changes in the amplitude of melatonin secretion at the time of puberty 24,78 . Neither the inverse correlation between melatonin and gonadal activity during normal development, nor the positive correlation between elevated melatonin and delayed puberty reported by Gupta ${ }^{39}$ provide firm evidence for a causal link between the decreasing amplitude of nocturnal melatonin secretion and sexual maturation. This notion is even less compelling if one recognizes that during puberty in boys, the daily increase in circulating luteinizing hormone concentrations occurs concomitantly with the nocturnal increase in melatonin secretion ${ }^{26}$. This line of reasoning can extend to animal studies which contend that melatonin provides a seasonal timekeeping cue, not an antigonadal signal. If melatonin were simply an antigonadal hormone, then puberty in sheep would not be expected to occur in the autumn when the daylength is decreasing, and thus, the total amount of nocturnal melatonin secretion increases. Conversely, precocious puberty would be predicted in a sheep in which rhythmic melatonin secretion is ablated (pinealectomy, superior cervical ganglionectomy) at birth; this does not oc$\operatorname{cur}^{33,48,96 .}$.

It might be argued that the sheep and other non-primate species which begin reproductive activity when the duration of melatonin secretion expands do not provide suitable models for human development, and that the entire issue must be investigated in a primate. Recent studies in sub-human primates also provide evidence to oppose the view that melatonin is antigonadal. It has become clear that puberty in the rhesus monkey, maintained in natural photoperiod, occurs in the autumn of the third or, more usually, fourth year of life ${ }^{90,94}$. Importantly, this seasonal pattern can be advanced by giving melatonin injections in the late afternoon to prepubertal monkeys, thereby extending the duration of the nightly melatonin rise ${ }^{91}$ (fig. 4). Thus, at least one well-studied sub-human primate, as well as the sheep, can respond to a lengthening of the duration of melatonin secretion as a stimulus for reproductive development. Moreover, pinealectomy of infantile male rhesus monkeys does not prevent the onset of the juvenile hypogonadotrophic state ${ }^{60}$. In view of the foregoing considerations, it is unlikely that pineal products are involved in maintaining prepubertal sexual immaturity. It is concluded that although the melatonin rhythm generating system is fully competent in man, we have evolved such that the timing of puberty is no longer linked to a particular season of the year, and therefore, 


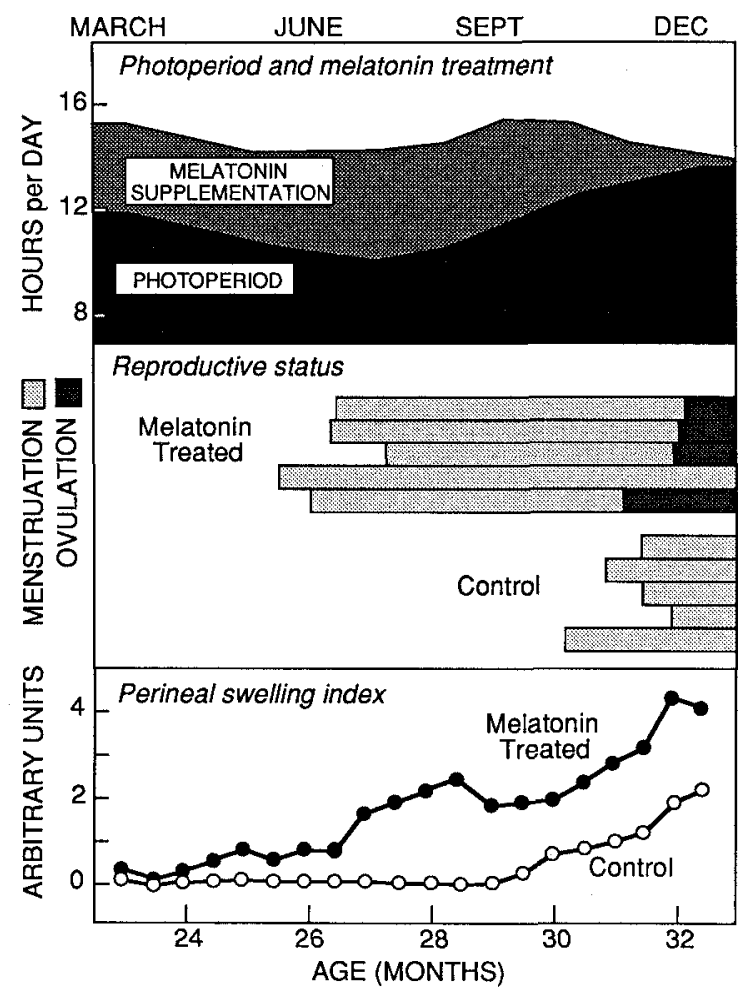

Figure 4. Melatonin treatment advances the age and season of reproductive maturation in female rhesus monkeys. Top: expected duration of elevated serum melatonin concentrations in control rhesus monkeys on natural photoperiod (solid area) and in monkeys receiving a single melatonin injection per day in the afternoon to increase the duration of elevated melatonin (shaded and solid area). Middle: timing of menarche (light bars) and ovulation (dark bars) in individual melatonin-treated and control monkeys. Bottom: group mean perineal swelling and colouration scores for melatonin-treated ( ) and control monkeys $(O), n=5$ per group. (Modified from Wilson and Gordon ${ }^{91}$ ).

the developing reproductive axis does not need to respond to the endogenous melatonin signal.

\section{Future directions}

We now have some understanding of the nature of photoperiodic signals that time puberty in several species, and of the mechanisms by which melatonin rhythms are generated by the pineal gland and transduce photoperiodic information; such information may be of practical importance in the regulation of animal populations. The challenge now is to understand where and how the melatonin signal acts in the brain to influence neuroendocrine function during development. Although some progress is being made to characterize receptors ${ }^{18}$ (Morgan and Williams, this issue) and identify anatomically the sites of action of melatonin ${ }^{82,89}$, perhaps the greatest challenge is to understand at the cellular and molecular level how the duration of melatonin is interpreted in relation to the previous pattern of melatonin secretion to provide seasonal information. The findings in the Djungarian hamster by Weaver and Reppert ${ }^{87}$ that just two days of melatonin information reaching the foetus can dictate subsequent reproductive responses to photoperiod suggest that reproductive maturation in mammals may provide a rapid and sensitive model for future studies of the mechanism of action of this important pineal product.

Acknowledgments. We thank Mrs Betty Lewis for assistance with typing this manuscript. Research on the developing sheep was supported by research and training grants from the NIH (HD-07048, HD-18258, HD18394 and Biomedical Support to the Vice President for Research at The University of Michigan), a Fulbright Travel Award and Fogarty Fellowship (TWO3766 to FJPE). We acknowledge permission from Endocrinology to reproduce the figures 1,2 and 3, and from Journal of Reproduction and Fertility for reproduction of figure 4.

1 Attanasio, A., Rager, K., and Gupta, D., Ontogeny of circadian rhythmicity for melatonin, serotonin and $\mathrm{N}$-acetylserotonin in humans. J. Pineal Res. 3 (1986) 251-256.

2 Bartness, T. J., and Goldman, B. D., Peak duration of serum melatonin and short-day responses in adult Siberian hamsters. Am. J. Physiol. 255 (1988) R812-R822.

3 Bartness, T. J., and Goldman, B. D., Effects of melatonin on longday responses in short-day housed adult Siberian hamsters. Am. J. Physiol. 255 (1988) R823-R830.

4 Bartness, T. J, and Goldman, B. D., Mammalian pineal melatonin: A clock for all seasons. Experientia 45 (1989) 939-945.

5 Bassett, J. M., Bomford, J, and Mott, J. C., Photoperiod: an important regulator of plasma prolactin concentration in fetal lambs during late gestation. Quart. J. exp. Physiol. 73 (1988) $241-244$.

6 Boyd, I. L., The effect of photoperiod and melatonin on testis development and regression in wild European rabbits (Oryctolagus cuniculus). Biol. Reprod. 33 (1985) 21-29.

7 Brackmann, M., and Hoffman, K., Pinealectomy and photoperiod influence testicular development in the Djungarian hamster. Naturwissenschaften 64 (1977) $341-342$.

8 Bronson, F. H., and Rissman, E. F., The biology of puberty. Biol. Rev. 61 (1986) 157-195.

9 Brown, B., and Forbes, J. M., Diurnal variations of plasma prolactin in growing sheep under two lighting regimes and the effect of pinealectomy. J. Endocr. 84 (1980) $91-99$.

10 Cameron, J. L., Hansen, P. D., McNeill, T. M., Koerker, D. J., Clifton, D. K., Rogers, K. V., Bremner, W. S., and Steiner, R. A., Metabolic cues for the onset of puberty in primate species, in: Adolescence in Females, p. 59-78. Eds C. Flamigni, S. Venturoli and J. R. Givens. Year Book Medical Publishers, Chicago 1985.

11 Carter, D. S., and Goldman, B. D., Antigonadal effects of timed melatonin infusion in pinealectomized male Djungarian hamsters (Phodopus sungoris sungoris): duration is the critical parameter. Endocrinology 113 (1983) $1261-1267$.

12 Carter, D. S., and Goldman, B. D., Progonadal role of the pineal in the Djungarian hamster: mediation by melatonin. Endocrinology 113 (1983) 1268-1273.

13 Charlton, H. M., Grocock, C. A., and Ostberg, A., The effects of pinealectomy and superior cervical ganglionectomy on the testis of the vole, Microtus agrestis. J. Reprod. Fert. 48 (1976) 377-379.

14 Claypool, L. E., Wood, R. I., Yellon, S. M., and Foster, D. L., The ontogeny of melatonin secretion in the lamb. Endocrinology (in press).

15 Darrow, J. M., Davis, F. C., Elliott, J. A., Stetson, M. H., Turek, F. W., and Menaker, M., Influence of photoperiod on reproductive development in the golden hamster. Biol. Reprod. 22 (1980) 443450 .

16 Darrow, J. M., and Goldman, B. D., Circadian regulation of pineal melatonin and reproduction in the Djungarian hamster. J. biol. Rhythms 1 (1986) 39-54.

17 Day, M. L., Imakawa, K., Zalesky, D. D., Kittok, R. J., and Kinder, J. E., Effects of restriction of dietary energy intake during the prepubertal period on secretion of luteinizing hormone and responsiveness of the pituitary to luteinizing hormone-releasing hormone in heifers. J. Anim. Sci. 62 (1986) 1641-1648.

18 Dubocovich, M. L., Pharmacology and function of melatonin receptors. FASEB J. 2 (1988) 2765-2773.

19 Ducker, M. J., Bowman, J. C., and Temple, A., The effect of constant photoperiod on the expression of oestrus in the ewe. J. Reprod. Fert. Suppl. 19 (1973) $143-150$. 
20 Ebling, F. J. P., and Foster, D. L., Photoperiod requirements for puberty differ from those for onset of the adult breeding season in sheep. J. Reprod. Fert. 84 (1988) 283-293.

21 Ebling, F. J. P., and Lincoln, G. A., $\beta$-Endorphin secretion in rams related to season and photoperiod. Endocrinology 120 (1987) 809 818 .

22 Ebling, F. J. P., Claypool, L. E., and Foster, D. L., Neuroendocrine responsiveness to light during the neonatal period in the sheep. $J$. Endocr. 119 (1988) 211-218

23 Ebling, F. J. P., Wood, R. I., Suttie, J. M., Adel, T. E., and Foster, D. L., Prenatal photoperiod influences neonatal prolactin secretion in the sheep. Endocrinology 125 (1989) 384-391.

24 Ehrenkrantz, J. R. L., Tamarkin, L., Comite, F., Johnsonbaugh, R. E., Bybee, D. E., Loriaux, D. L., and Cutler, G. B., Daily rhythm of plasma melatonin in normal and precocious puberty. J. clin. Endocr. Metab. 55 (1982) 307-310.

25 Eisemann, J. H., Bauman, D. E., Hogue, D. E., and Travis, H. F. Influence of photoperiod and prolactin on body composition and in vitro lipid metabolism in wether lambs. J. Anim. Sci. 59 (1984) 95-104.

26 Fevre, M., Segel, T., Marks, J. M., and Boyar, R. M., LH and melatonin secretion patterns in pubertal boys. J. clin. Endocr. Metab. 47 (1979) 1383-1386.

27 Follett, B. K., Photoperiodism and seasonal breeding in birds and mammals in: Control of Ovulation, p. 267-293. Eds D. B. Creighton, G. R. Foxeroft, N. B. Haynes, and G. E. Lamming. Butterworths, London 1978.

28 Forbes, J. M., Driver, P. M., Brown, W. B., Scanes, C. G., and Hart I. C., The effect of daylength on the growth of lambs. 2. Blood concentrations of growth hormone, prolactin, insulin and thyroxine and the effect of feeding. Anim. Prod. 29 (1979) 43.

29 Foster, D. L., Comparative development of mammalian females: proposed analogies among patterns of $\mathrm{LH}$ secretion in various species, in: Problems in Pediatric Endocrinology, p. 193-210. Eds C. La Cauza and A. W. Root. Academic Press, London 1980.

30 Foster, D. L., Mechanism for delay of first ovulation in lambs born in the wrong season (fall). Biol. Reprod. 25 (1981) 85-92.

31 Foster, D. L., and Olster, D. H., Effect of restricted nutrition on puberty in the lamb: patterns of tonic luteinizing hormone ( $\mathrm{LH}$ ) secretion and competency of the LH surge system. Endocrinology 116 (1985) 375-381.

32 Foster, D. L., Ebling, F. J. P., and Claypool, L. E., Timing of puberty by photoperiod. Reprod. Nutr. Develop. 28 (1988) 349-364.

33 Foster, D. L., Ebling, F. J. P., Claypool, L. E., and Woodfill, C. J. I., Cessation of long-day melatonin rhythms time puberty in a shortday breeder. Endocrinology 123 (1988) 1636-1641.

34 Foster, D. L., Karsch, F. J., Olster, D. H., Ryan, K. D., and Yellon, S. M., Determinants of puberty in a seasonal breeder. Rec. Prog. Horm. Res. 42 (1986) 330-384.

35 Foster, D. L., Yellon, S. M., Ebling, F. J. P., and Claypool, L. E., Are ambient short-day cues necessary for puberty in a short-day breeder? Biol. Reprod. 38 (1988) $821-829$

36 Goldman, B. D., The physiology of melatonin in mammals, in: Pineal Research Reviews, p. $145-182$. Ed. R. J. Reiter. Alan R. Liss, New York 1983.

37 Goldman, B. D., and Darrow, J. M., The pineal gland and mammalian photoperiodism. Neuroendocrinology 37 (1983) 386-396.

38 Goldman, B. D., Darrow, J. M., and Yogev, L., Effects of timed melatonin infusions on reproductive development in the Djungarian hamster (Phodopus sungorus). Endocrinology 114 (1984) 2076-2083.

39 Gupta, D., Human development and the pineal gland in: The Pineal Gland During Development: From Fetus to Adult, p. 117-133. Eds D. Gupta and R. J. Reiter. Croom Helm, London 1986.

40 Hartmann, L., Roger, M., Lemaitre, B. J., Massias, J. F., and Chaussain, J. L., Plasma and urinary melatonin in male infants during the first 12 months of life. Clinica chim. Acta 121 (1982) 37-42.

41 Hastings, M. H., Herbert, J., Hutchinson, J., Powers, J. B., Steel, E. A., and Walker, A. P., Differential neuroendocrine effects on photoperiodic history on the response of gonadotrophins and prolactin to intermediate day-lengths in the male Syrian hamster. J. biol. Rhythms (1989) in press.

42 Hoffman, K., Effect of short photoperiods on puberty, growth, and moult in the Djungarian hamster (Phodopus sungoris). J. Reprod. Fert. 54 (1978) 29-35.

43 Hoffman, K., Illnerova, H., and Vanecek, J., Change in duration of the nighttime melatonin peak may be a signal driving photoperiodic responses in the Djungarian hamster. Neurosci. Lett. 67 (1986) 6872.
44 Horton, T. H., Cross-fostering of voles demonstrates in utero effects of photoperiod. Biol. Reprod. 33 (1985) 934-939.

45 Horton, T. H., Growth and reproductive development of male $\mathrm{Mi}$ crotus montanus is affected by the prenatal photoperiod. Biol. Reprod. 31 (1984) $499-504$

46 Karsch, F. J., Bittman, E. L., Foster, D. L., Goodman, R. L., Legan, S. J., and Robinson, J. E., Neuroendocrine basis of seasonal reproduction. Rec. Prog. Horm. Res. 40 (1984) 185-232.

47 Kennaway, D. J., and Gilmore, T. A., Effects of melatonin implants in ewe lambs. J. Reprod. Fert. 70 (1984) 39-45.

48 Kennaway, D. J., Gilmore, T. A., and Dunstan, E. A., Pinealectomy delays puberty in ewe lambs. J. Reprod. Fert. 74 (1985) 119-125.

49 Kennedy, G. C., and Mitra, J., Body weight and food intake as initiating factors for puberty in the rat. J. Physiol. 166 (1963) $408-$ 418 .

50 Klein, D. C., Evidence for the placental transfer of ${ }^{3} \mathrm{H}$-acetyl-melatonin. Nature 237 (1972) 117

51 Lee, T. M., Smale, L., Zucker, I., and Dark, J., Influence of daylength experienced by dams on post-natal development of young meadow voles (Microtus pennsylvanicus) J. Reprod. Fert. 81 (1987) $337-342$.

52 Lee, T. M., and Zucker, I., Vole infant development is influenced perinatally by maternal photoperiodic history Am. J. Physiol. 255 (1988) R831-R838.

53 Lincoln, G. A., Light-induced rhythms of prolactin secretion in the ram and the effect of cranial sympathectomy. Acta endocr. 91 (1979) $421-427$

54 Lincoln, G. A., and Ebling, F. J. P., Effect of constant-relase implants of melatonin on seasonal cycles in reproduction, prolactin secretion and moulting in rams. J. Reprod. Fert. 73 (1985) $241-253$.

55 Lincoln, G. A., McNeilly, A. S., and Cameron, C. L., The effects of a sudden decrease or increase in daylength on prolactin secretion in the ram. J. Reprod. Fert. 52 (1978) 305-311.

56 McMillen, I. C., and Nowak, R., Maternal pinealectomy abolishes the diurnal rhythm in melatonin concentrations in the fetal sheep. $\mathrm{J}$. Reprod. Fert. Abstract Ser. 1 (1988) 19.

57 Moller, W. The human foetal pineal gland. Morphological indications of a photoreceptive capacity, in: The Pineal Gland During Development: From Fetus to Adult, p. 80-88. Ed's D. Gupta and R. J. Reiter. Croom Helm, London 1986.

58 Nowak, R., and Rodway, R. G., Effect of intravaginal implants of melatonin on the onset ovarian activity in adult and prepubertal ewes. J. Reprod. Fert. 74 (1985) 287-293.

59 Oldham, C. M., and Gray, S. J., The 'ram effect' will advance puberty in 9 or 10 month old merino ewes independent of the season of birth. Proc. Aust. Soc. Anim. Prod. 15 (1984) 727-728.

60 Plant, T. M., and Zorub, D. S., Pinealectomy in agonadal infantile male rhesus monkeys (Macaca mulatta) does not interrupt initiation of the prepubertal hiatus in gonadotropin secretion. Endocrinology 118 (1986) 227-232.

61 Radford, H. M., Photoperiodism and sexual activity in Merino ewes. Aust. J. Agric. Res. 12 (1960) 139-153.

62 Reiter, R. J., The pineal gland and pubertal development in mammals: a state of the art assessment, in: The Pineal Gland During Development: From Fetus to Adult, p. 100-116. Eds D. Gupta and R. J. Reiter. Croom Helm, London 1986.

63 Reppert, S. M., Chez, R. A., Anderson, A., and Klein, D. C., Maternal-fetal transfer of melatonin in the non-human primate. Pediatric Res. 13 (1979) $788-791$.

64 Rissman, E. F., Prepubertal sensitivity to melatonin in male hamsters. Biol. Reprod. 22 (1980) $277-280$

65 Robinson, J. E., and Karsch, F. J., Photoperiodic history and a changing melatonin pattern can determine the neuroendocrine response of the ewe to daylength. J. Reprod. Fert. 80 (1987) 159-165.

66 Rollag, M. D., and Stetson, M. H., Ontogeny of the pineal melatonin rhythm in golden hamsters. Biol. Reprod. 24 (1981) 311.

67 Rollag, M. D., Dipinto, M. N., and Stetson, M. H., Ontogeny of the gonadal response of golden hamsters to short photoperiod, blinding, and melatonin. Biol. Reprod. 27 (1982) $898-902$

68 Ryan, K. D., and Robinson, S. L., A rise in tonic luteinizing hormone secretion occurs during photoperiod-stimulated sexual maturation of the female ferret. Endocrinology 116 (1985) $2013-$ 2018.

69 Ryan, K. D., Maturation of ovarian function in female ferrets is influenced by photoperiod. J. Reprod. Fert. 74 (1985) 503-507.

70 Silman, R. E., Leone, R. M., Hooper, R. J. L., and Preece, M. A. Melatonin, the pineal gland and human puberty. Nature 282 (1979) $301-303$. 
71 Sisk, C. L., and Turek, F. W., Developmental time course of pubertal and photoperiodic changes in testosterone negative feedback on gonadotropin secretion in the golden hamster. Endocrinology 112 (1.983) $1208-1216$

72 Smith, A. J., Mondain-Monval, M., Andersen Berg, K., Simon, P., Forsberg, M., Clausen, O.P.F., Hansen, T., Moller, O. M., and Scholler, R., Effects of melatonin implantation on spermatogenesis, the moulting cycle and plasma concentrations of melatonin, $\mathrm{LH}$, prolactin and testosterone in the male blue fox (Alopex lagopus). $\mathrm{J}$. Reprod. Fert. 79 (1987) 379-390.

73 Smith, I. D., The effect of constant long daily photoperiod upon the onset of puberty in ewes. J. agric. Sci. 69 (1967) 43-45.

74 Sorrentino, S. Jr, Reiter, R. J., and Schalch, D. S., Interactions of the pineal gland, blinding, and underfeeding on reproductive organ size and radioimmunoassayable growth hormone. Neuroendocrinology 7 (1971) 105-115.

75 Stansfield, S. C., Knight, P. G., Al-Mauly, N. Z., and Bryant, M. J., Involvement of endogenous opioid peptides in the neuroendocrine response of ewe lambs to the introduction of a ram. J, Endocr. 115 (1987) 333-339.

76 Stetson, M. H., Elliott, J. A., and Goldman, B. D., Maternal transfer of photoperiodic information influences the photoperiodic response of prepubertal Djungarian hamsters. Biol. Reprod. 34 (1986) $664-$ 669.

77 Steiner, R. A., Metabolic cues for the onset of puberty in subhuman primates. Proc. Nutr. Soc. 46 (1987) 159-175.

78 Tamarkin, L., Abastillas, P., Chen, H-C., McNemar, A., and Sidbury, J. B., The daily profile of plasma melatonin in obese and Prader-Willi-syndrome children. J. clin. Endocr. Metab. 55 (1982) $491-495$.

79 Tamarkin, L., Reppert, S. M., Orloff, D. J., Klein, D. C., Yellon, S. M., and Goldman, B. D., Ontogeny of the pineal melatonin rhythm in the Syrian (Mesocricetus auratus), and Siberian (Phodopus sungoris) hamsters and in the rat. Endocrinology 107 (1980) 1061 1064.

80 Turek, F. W., Effect of melatonin on photic-independent and photicdependent testicular growth in juvenile and adult male golden hamsters. Biol. Reprod. 20 (1979) 1119-1122.

81 Ueck, M., The morphogenesis of the mammalian pineal organ, in: The Pineal Gland During Development: From Fetus to Adult, p. 43-55. Eds D. Gupta and R. J. Reiter. Croom Helm, London 1986.

82 Vanacek, J., Pavlik, A., and Illnerova, H., Hypothalamic melatonin receptor sites revealed by autoradiography. Brain Res. 435 (1987) $359-362$.

83 Vollrath, L., The postnatal differentiation of the mammalian pineal complex, in: The Pineal Gland During Development: From Fetus to Adult, p. 56-66. Eds D. Gupta and R. J. Reiter. Croom Helm, London 1986.

84 Waldhauser, F., and Gisinger, B., The pineal gland and its development in human puberty, in: The Pineal Gland During Development: From Fetus to Adult, p. 134-143. Eds D. Gupta and R. J. Reiter. Croom Helm, London 1986.
85 Waldhauser, F., Weizsenbacher, G., Tatzer, E., Gisinger, B., Waldhauser, M., Schemper, M., and Frisch, H., Alterations in nocturnal serum melatonin levels with growth and aging. J. clin. Endocr. Metab. 66 (1988) 648-652.

86 Wallen, E. P., and Turek, F. W., Photoperiodicity in the male albino laboratory rat. Nature 289 (1981) $402-404$.

87 Weaver, D. R., and Reppert, S. M., Maternal melatonin communicates daylength to the fetus in Djungarian hamsters. Endocrinology 119 (1986) $2861-2863$.

88 Weaver, D. R., Keohan, J. T., and Reppert, S. M., Definition of a prenatal sensitive period for maternal-fetal communication of daylength. Am. J. Physiol. 253 (1987) E701-E704.

89 Williams, L. M., and Morgan, P. J., Demonstration of melatoninbinding sites on the pars tuberalis of the rat. J. Endocr. 119 (1988) $\mathrm{R} 1-\mathrm{R} 3$.

90 Wilson, M. E., and Gordon, T. P., Season determines timing of first ovulation in outdoor-housed rhesus monkeys. J. Reprod. Fert. 85 (1989) $583-591$

91 Wilson, M. E., and Gordon, T. P., Short-day melatonin pattern advances puberty in seasonally breeding rhesus monkeys. J. Reprod. Fert. 86 (1989) $435-444$.

92 Wilson, M. E., and Gordon, T. P., Nocturnal changes in serum melatonin during female puberty in rhesus monkeys, a longitudinal study. J. Endocr. 121 (1989) 553-562.

93 Wilson, M. E., Gordon, T. P., Blank, M. S., and Collins, D. C., Timing of sexual maturity in female rhesus monkeys (Macaca mulatta) housed outdoors. J. Reprod. Fert. 70 (1984) 625-633.

94 Wilson, M. E., Gordon, T. P., Rudman, C. R, and Tanner, I. M., Effects of a natural versus artificial environment on the tempo of maturation in female rhesus monkeys. Endocrinology 123 (1988) 2653-2661.

95 Yellon, S. M., and Foster, D. L., Alternate photoperiods time puberty in the female lamb. Endocrinology 116 (1985) 2090-2097.

96 Yellon, S. M., and Foster, D. L., Melatonin rhythms time photoperiod-induced puberty in the female lamb. Endocrinology 119 (1986) 44-49.

97 Yellon, S. M., and Goldman, B. D., Photoperiod control of reproductive development in the male Djungarian hamster (Phodopus sungoris). Endoctinology 114 (1984) 664-670.

98 Yellon, S. M., and Longo, L. D., Effect of maternal pinealectomy and reverse photoperiod on the circadian melatonin rhythm in the sheep and fetus during the last trimester of pregnancy. Biol. Reprod. 39 (1988) 1093-1099.

99 Yellon, S. M., and Longo, L. D., Melatonin rhythms in fetal and maternal circulation during pregnancy in sheep. Am. J. Physiol. 252 (1987) E799-E802.

100 Zemdegs, I. Z., McMillen, I. C., Walker, D. W., Thorburn, G. D., and Nowak, R., Diurnal rhythms in plasma melatonin concentrations in the fetal sheep and pregnant ewe during late gestation. Endocrinology 123 (1988) 284-289

0014-4754/89/10946-09\$1.50+0.20/0

(C) Birkhäuser Verlag Basel, 1989 